\title{
Alcohol intoxication among adolescents and children in urban and rural environments - a retrospective analysis
}

\author{
Agnieszka Pawłowska-Kamieniak', Agnieszka Mroczkowska-Juchkiewicz', Katarzyna Kominek', \\ Paulina Krawiec ${ }^{1}$, Beata Mełges ${ }^{1}$, Elżbieta Pac-Kożuchowska' \\ ${ }^{1}$ Department of Paediatrics, Medical University of Lublin, Poland
}

Pawłowska-Kamieniak A, Mroczkowska-Juchkiewicz A, Kominek K, Krawiec P, Mełges B, Pac-Kożuchowska E. Alcohol intoxication among adolescents and children in urban and rural environments - a retrospective analysis. Ann Agric Environ Med. 2018; 25(1): 1-3. doi: $10.5604 / 12321966.1228397$

\begin{abstract}
Introduction and objective. Drinking alcohol by adolescents and children poses a risk of long-term psychological and sociological consequences, often leading to addiction in adulthood. A steady increase in the number of young people reaching for alcohol is worrying. The study analyzes the age and gender of the children, concentration of alcohol in the blood, depending on the origin of the youth (urban or rural).

Material and method. The study was a retrospective analysis of 402 patients hospitalized due to alcohol intoxication in the Department of Paediatrics at Medical University in Lublin, Poland between 2004 - 2013.

Results. During the study period a continuous increase in admissions of patients after alcohol consumption was observed: from 27 children in 2004 to 53 in 2012 and 2013. The youngest patient hospitalized after drinking was 7.6 years old and came from the rural environment, the oldest 18 years old and came from the urban environment. In 2004 - 2007, boys dominated among children intoxicated with alcohol; since 2008, a slight prevalence of girls has been observed, especially in the urban environment. Among patients coming from the country, boys always predominated. In the study period there was noted a similar number of children consuming alcohol from rural and urban environments.

Conclusions. The results suggest the need to introduce appropriate educational programmes in schools to prevent the consumption of alcohol at a young age.
\end{abstract}

\section{Key words}

children, adolescents, alcohol intoxication, village, town

\section{INTRODUCTION}

Drinking alcohol by young people is one of the major social problems in Europe. Alcohol consumption can cause a variety of immediate and late effects. Not only ethanol is very rapidly absorbed from the gastrointestinal tract and is toxic, but also its metabolite - acetic aldehyde. The consequences of intoxicationdepending on the patient's age and the amount and type of alcohol consumed, as well as individual sensitivity- include impaired consciousness, or sometimes loss of consciousness. Alcohol intoxication can be life-threatening and affects the respiratory, cardiovascular system and causes metabolic disorders. Reduction of motor function leads to life-threatening injuries. Alcohol consumption hampers not only the physical and psychological states, but also social development, causes memory loss and chronic damage to many vital organs which often leading to addiction. It is known that neural pathways continue to develop throughout childhood and adolescence. The influence of permanent alcohol consumption is indisputable [1]. Based on many studies, it is observed that the number of children and young people reaching for alcoholic beverages continues to grow, both in rural and urban environments. Children often imitate the reprehensible behaviour of their parents; they also reach for alcohol in an attempt to impress colleagues $[2,3,4,5,6,7,8,9,10]$.

Address for correspondence: Agnieszka Pawłowska-Kamieniak, Department of Paediatrics, Medical University of Lublin, Poland

E-mail: akamieniak@poczta.onet.pl

Received: 14 January 2014; accepted: 8 July 2015; first published on December, 2016
The continuous increase in hospital admissions of alcoholintoxicated girls, regardless of their origin (urban or rural), is of special concern because of the long-term consequences. Mothers of children born with foetal alcohol syndrome or women giving birth in a state of alcohol intoxication, often reach for alcohol for the first time before reaching adulthood [10].

Strengthening of unfavourable behaviour among youth necessitates analyzing the reasons for this phenomenon.

\section{OBJECTIVE}

The aim was to analyze the age and gender of intoxicated children, concentration of alcohol in the blood, depending on origin of the youth (urban or rural). Patients' characteristics were obtained from medical records, retrospectively. Many patients were hospitalized only for several hours, and in some cases taking medical history was incomplete. Therefore, social history, including school or family problems, were not analyzed.

\section{MATERIALS AND METHOD}

The study was a retrospective analysis of 402 patients hospitalized due to alcohol intoxication in the Department of Paediatrics at the Medical University in Lublin, Poland, between 2004-2013. 


\section{RESULTS}

Among patients intoxicated with ethanol the youngest child who was treated at the Department of Paediatrics was 7.6 years old and the child was of rural origin. The oldest patient was 18 years of age and came from the urban environment. The age of patients intoxicated with alcohol in the studied period in the two environments was similar (Tab. 1).

Table 1. Age of children more than ten years old from urban and rural environments hospitalized in the Department of Paediatrics after intoxication with alcohol

\begin{tabular}{lcc}
\hline \multirow{2}{*}{ YEAR } & \multicolumn{2}{c}{ AGE OF CHILDREN INTOXICATED WITH ALCOHOL } \\
& TOWIN - MAX) & \\
\cline { 2 - 3 } & $12.4-15.5$ & VILLAGE \\
\hline 2004 & $10.9-16.6$ & $12.5-14.9$ \\
\hline 2005 & $9.7-16.9$ & $7.6-17.3$ \\
\hline 2006 & $12.1-15.9$ & $10.9-17.2$ \\
\hline 2007 & $10.6-17.7$ & $12.0-15.7$ \\
\hline 2008 & $11.1-16.5$ & $12.3-16.8$ \\
\hline 2010 & $12.9-18.0$ & $10.6-15.5$ \\
\hline 2011 & $11.0-17.6$ & $12.0-17.9$ \\
\hline 2012 & $12.0-16.4$ & $13.3-17.0$ \\
\hline 2013 & $11.8-16,0$ & $12.0-16.7$ \\
\hline
\end{tabular}

The lowest determined level of ethanol among the children intoxicated with alcohol was $0.1 \%$, in a patient coming from the country, the highest $-3.9 \%$, in a child of urban origin (Tab. 2).

Table 2. Alcohol concentration in blood of children from urban and rural environments hospitalized in the Department of Paediatrics after the intoxication with alcohol during the research period

\begin{tabular}{lcc}
\hline \multirow{2}{*}{ YEAR } & \multicolumn{2}{c}{ ALCOHOL CONCENTRATION } \\
\cline { 2 - 3 } & (MIN - MAX \%o) IN BLOOD OF ALCOHOL-INTOXICATED CHILDREN \\
\hline 2004 & $0.8-3.2$ & VILLAGE \\
\hline 2005 & $0.5-3.5$ & $1.0-2.6$ \\
\hline 2006 & $0.7-2.5$ & $0.1-1.9$ \\
\hline 2007 & $1.4-3.3$ & $1.4-3.4$ \\
\hline 2008 & $1.0-2.6$ & $0.8-3.5$ \\
\hline 2009 & $0.2-2.9$ & $0.6-3.3$ \\
\hline 2010 & $0.7-3.1$ & $0.9-2.3$ \\
\hline 2011 & $1.1-2.9$ & $0.9-2.2$ \\
\hline 2012 & $1.2-3.9$ & $0.8-2.8$ \\
\hline 2013 & $0,1-2,83$ & $1.0-3.4$ \\
\hline
\end{tabular}

When analyzing the cases of alcohol intoxication, a continuously increasing incidence of hospital admissions of children after alcohol consumption was observed - from 27 children in 2004 to 53 in 2012 and 2013 (Fig. 1). In the analyzed period, the great majority -258 children (64.18\%) came from towns. A permanent prevalence was observed in the hospitalized children of urban origin over the patients from rural regions intoxicated with alcohol (Fig. 1).

Among children with alcohol intoxication, in the evaluated years in the Department of Paediatrics, there were

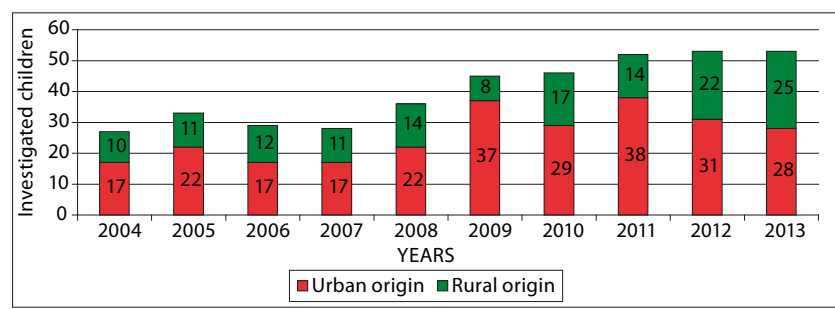

Figure 1. Number and origin of children hospitalized after alcohol intoxication $2004-2013$

hospitalized 230 boys, most of whom, i.e. $60 \%$, were of urban origin. 172 girls treated, of whom $69.77 \%$ came from towns (Fig. 2). A strong increase in the number of hospitalized girls intoxicated with alcohol was observed. Among the children of urban origin investigated since 2008, the number of boys and girls hospitalized after alcohol consumption was comparable (Fig. 3). Among children intoxicated with alcohol and coming from rural environment boys dominated in each of the studied years.

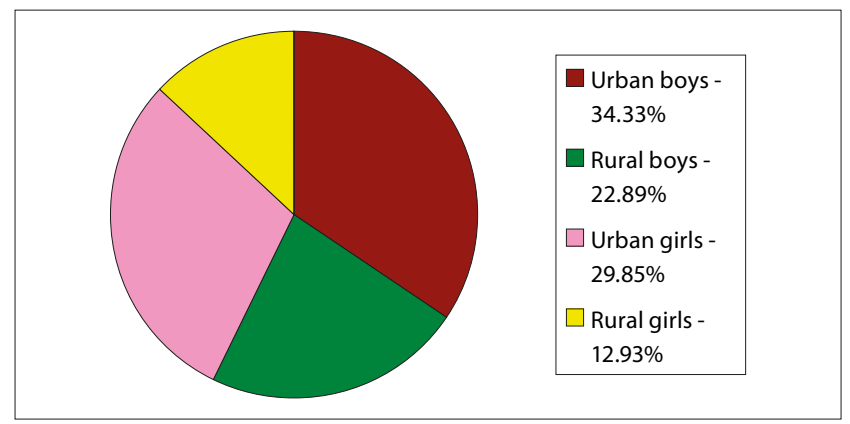

Figure 2. Origin and gender of children hospitalized after alcohol intoxication $2004-20132004-2013$

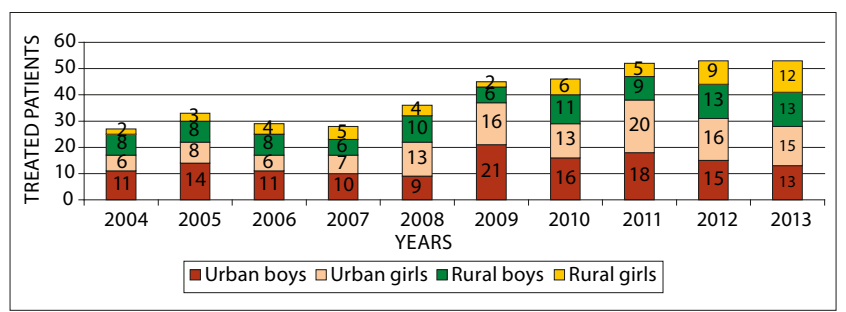

Figure 3. Gender of children hospitalized due to alcohol intoxication 2000-2013

\section{DISCUSSION}

On analyzing the cases of intoxication in the presented study, a continuously increasing incidence was observed of the hospitalization of children after consuming alcohol from 27 cases in 2004 to 53 in 2012 and 2013, reflecting the persistence and increasing trend of this adverse event. Bitunjac et al. in their retrospective study covering the period 1997 - 2007, showed an increase in hospitalizations due to intoxication from $16.7 \%-66.3 \%$ [11]. The higher consumption of alcohol by young people may be associated with increased access to alcohol, and the increased need to attract the attention of family environment or peers. The problem of an increasing incidence of hospitalization after the consumption of alcohol among the paediatric population was also noted by Crosssland et al, who took into account the age of the patients and the prevalence of teenagers, the more frequent use of 
alcohol in the evening among friends, away from home [3].

A comparable number of children of urban and rural origin proves that the problem of alcohol consumption by children and adolescents refers to any environment. It may also testify to easy access to alcohol, regardless of place of residence, both in urban and rural environments. The research by Huk-Wieliczuk et al. conducted in 2001 and 2002 among 402 rural students aged 15 and 17 years, showed that more than $82 \%$ of students had already consumed alcohol. The conducted survey confirmed that in the preceding 12 months, $83 \%$ of 15 -year-old and $95 \%$ of 17 -year-old students had drunk alcohol [7].

Among the paediatric population, teenagers consume alcohol most frequently [2, 3, 4, 5, 6, 9, 11], but the analysis clearly indicates that there are cases of alcohol intoxication in very young children, as a result of accidental ingestion or pathological effect of relationships and intra-family conditions.

Antoniette et al. suggested that ethanol consumption early in life increases the risk of alcohol abuse and alcohol use disorders in adulthood [10]. In the period evaluated for the current study, the youngest intoxicated patient was 7.6 years old, but the circumstances of alcohol consumption were not known. However, there was no follow-up of any of the patients, and therefore a lack of information about their further use of alcohol or other psychoactive substances.

The case of alcohol intoxication even in a two-year-old patient was described by Malcolm et al.; in this case, the cause of intoxication was also not known [2]. Bitunjac et al. in their retrospective work demonstrated 2 cases of alcohol intoxication in the age group of $0-5$ years, 4 cases in the age group from $6-9$ years [11]. The research by Kabata shows that $80.6 \%$ of children aged $11-16$ years consumed alcohol at least once in their lives [8]. Weinberg et al. in their retrospective work showed that the average age of patients hospitalized due to of alcohol intoxication was 14.5 years [4]. Similarly, rosssland et al. noted that in the evaluated period from November 1999 - October 2000, 3/4 of patients (77\%) were aged 13 - 15 years [3].

The ever-increasing number of girls reaching for alcohol seems to be a worrying phenomenon. Females are usually less associated with inadequate behaviour, stimulants, and willingness to experiment. Alcohol consumption by young girls, who in the future will be mothers, is particularly dangerous [13]. In the presented study, boys initially dominated. From 2008, a similar incidence of hospitalization we observed due to alcohol intoxication in boys and girls. Crossland, covering only a one-year follow-up (November 1999 - October 2000, respectively) reported a slight advantage among female alcohol-intoxicated patients [3]. Weinberg noted a comparable number of boys and girls intoxicated with alcohol [3]. Woolfenden, in turn, indicated a slight prevalence of males - 53\% [6]. Similarly, Bitunjac et al. in their retrospective work reported in the studied period a growth in hospitalizations of alcohol-intoxicated girls, from one case in the first year to 15 cases in the last year of study [11].
The influence of permanent alcohol consumption for the maturation of the juvenile brain is indisputable $[1,10]$. In the current study, occasional, usually only once in a lifetime, overuse of alcohol by young people was observed. Generally, alcohol drinking among young people is one of the major social problems in Europe. The early age of alcohol initiation may be an indicator of alcohol disorders in adulthood $[10,12]$. The observed increase in the incidence of alcohol intoxication in young people in the context of possible adverse consequences in future, should lead to the mandatory launching of adequate educational programmes on alcohol-related harm at the stage of primary schools.

\section{CONCLUSIONS}

1. There has been observed a steady increase in alcohol consumption among children and adolescents.

2. Over the years, there have been an increasing number of girls drinking alcohol.

3. In recent years, there has been a lack of environmental determinants among young people hospitalized due to alcohol consumption.

\section{REFERENCES}

1. Paus T, Zijdenbos A, Worsley K, Collins DL, Blumenthal J, Giedd JN, et al. Structural maturation of neural pathways in children and adolescents: in vivo study. Science 1999; 283: 1908-1911.

2. Malcolm JB, Benjamin B, Sorbie A, Auchterlonie IA. Alcohol intoxication, an underdiagnosed problem? Arch Dis Child. 1985; 60 (8): 762-763.

3. Crossland D, Potier De La Morandiere K. Alcopops are not responsible for acute paediatric attendances alcohol intoxication. Arch Dis Child. 2001; 85: 268-269.

4. Weinberg L, Wyatt JP. Children presenting to hospital with acute alcohol intoxication. Emerg Med J. 2006; 23: 774-776.

5. Bukowska W, Szlagatys A, Korzon M. Zatrucia u dzieci i młodzieży nowe problemy. Przegl Ped. 2001; 31(1): 50-54 (in Polish).

6. Woofenden S, Dossetor D, Williams D. Children and Adolescences With Acute Alcohol Intoxication / Self-poisoning Presentating to the Emergency Department. Arch Pediatr Adolesc Med. 2002; 156 (4): 345-348.

7. Huk-Wieliczuk E, Litwiniuk A. Picie alkoholu przez uczniów wiejskich w wieku 15-17 lat. Zdr Publ. 2004; 114(3): 312-314 (in Polish).

8. Kabata B. Trudności w terapii uzależnienia od alkoholu z praktyki lekarza rodzinnego na wsi. Hygeia Public Health 2011; 46(3): 385-389 (in Polish).

9. Woolfenden S, Dossetor D, Williams K. Children and adolescents with acute alcohol intoxication/self poisoning presenting to the emergency department. Arch Pediatr Adolesc Med. 2002; 156(4): 345-348.

10. Maldonado-Devincci AM, Badanich KA, Kirstein CL. Alcohol during adolescence selectively alters immediate and long-term behawior and neurochemistry. Alcohol. 2010; 44: 57-66.

11. Bitunjac K, Saraga M. Alcohol intoxication In pediatric age: ten- year retrospective study. Croat Med J. 2009; 50: 151-156.

12. DeWit DJ, Adlaf EM, Offord DR, Ogborne AC. Age at first alcohol use: a risk factor for the development of alcohol disorders. Am J Psychiatry 2000; 157: 745-750.

13. Peadon E, Rhys-Jones B, Bower C, Elliott EJ. Systematic review of interventions for children with Fetal Alcohol Spectrum Disorders. BMC Pediatrics 2009; 9:35. 